\title{
IN VITRO COMPARISON OF HUMAN FIBROBLASTS FROM INTACT AND RUPTURED ACL FOR USE IN TISSUE ENGINEERING
}

\author{
T. Brune ${ }^{1,2 *}$, A. Borel ${ }^{1}$, T.W. Gilbert ${ }^{3}$, J.P. Franceschi ${ }^{4}$, S.F. Badylak ${ }^{3}$ and P. Sommer ${ }^{1}$ \\ ${ }^{1}$ Institut de Biologie et Chimie des Protéines, Centre National de la Recherche Scientifique - Université Claude \\ Bernard Lyon 1, Lyon, France \\ ${ }^{2}$ Natural Implant, Brest, France \\ ${ }^{3}$ McGowan Institute for Regenerative Medicine, Department of Surgery, University of Pittsburgh, Pittsburgh, PA, \\ USA. \\ ${ }^{4}$ Hôpital de la Conception, Centre Hospitalier Universitaire de Marseille, Marseille, France
}

\begin{abstract}
The present study compares fibroblasts extracted from intact and ruptured human anterior cruciate ligaments (ACL) for creation of a tissue engineered ACL-construct, made of porcine small intestinal submucosal extracellular matrix (SIS-ECM) seeded with these ACL cells. The comparison is based on histological, immunohistochemical and RT-PCR analyses. Differences were observed between cells in a ruptured ACL (rACL) and cells in an intact ACL (iACL), particularly with regard to the expression of integrin subunits and smooth muscle actin (SMA). Despite these differences in the cell source, both cell populations behaved similarly when seeded on an SIS-ECM scaffold, with similar cell morphology, connective tissue organization and composition, SMA and integrin expression. This study shows the usefulness of naturally occurring scaffolds such as SIS-ECM for the study of cell behaviour in vitro, and illustrates the possibility to use autologous cells extracted from ruptured ACL biopsies as a source for tissue engineered ACL constructs.
\end{abstract}

Key Words: Tissue engineering, anterior cruciate ligament, extracted fibroblasts, small intestinal submucosa scaffold, integrins, elastic network, in vitro models.

*Address for correspondence:

Thierry Brune

Institut de Biologie et Chimie des Protéines

Equipe Protéines matricielles et assemblage tissulaire

UMR 5086 CNRS - UCBL1

7, passage du Vercors

69367 Lyon cedex 07, France

Telephone Number: +33(0)472722666

FAX Number: +33(0)4 72722604

E-mail: thierry_brune@yahoo.fr
Introduction

A common approach to create a tissue engineered construct for replacement of injured tissue involves seeding a scaffold with a population of specific cells in vitro, followed by implantation of the constructs to the site of interest (Altman et al., 2002; Bellincampi et al., 1998; Laurencin and Freeman, 2005). The source of cells for creating such a construct is crucial for a successful outcome. Allogenic stem cells and primary differentiated cells have been investigated, and have shown some efficacy in clinical practice; however, immunotolerance of the cells is a concern. Autologous cells are widely studied because they pose no immunologic risk, but availability of these cells depends upon a source of healthy tissue, there is donor site morbidity risk, and the necessity for multiple procedures to harvest sufficient cells for culture and implantation. Few comparative studies have been conducted to determine the efficacy of cells from different sources for a particular application.

An example of a clinical application that may benefit from a cell seeded tissue engineered product is reconstruction of the anterior cruciate ligament (ACL). The ACL is important for anterior-posterior and rotatory stability of the knee (Gabriel et al., 2004; Loh et al., 2003), and does not spontaneously heal after a complete rupture. Without reconstruction of the ACL, many patients suffer from progressive deterioration of the articular cartilage of the knee, ultimately resulting in the need for a total knee arthroplasty. The present gold standard for ACL reconstruction is the use of an autologous tendon graft. Although the clinical results are generally good, the use of autologous tissue still has limitations, including different tissue morphology and innervation, and morbidity at the site of tissue harvest (Adachi et al., 2003; Aune et al., 1996; Kartus et al., 2001).

Possible cell sources for a cell seeded tissue engineered construct for the ACL would include autologous fibroblasts from either the ruptured ACL or from an intact contralateral ligament. Fibroblasts from the ruptured ACL remain viable and express collagen for at least 1 year after rupture (Spindler et al., 1996), although cell phenotype is altered due to the changes in the local biochemical and mechanical environment (Lo et al., 1998; Neurath et al., 1994). Fibroblasts are also able to migrate from ruptured ACL explants towards a collagen-GAG scaffold (Murray and Spector, 2001).

The goal of the present study was to characterize and compare fibroblasts from intact (iACL) and ruptured 
(rACL) ACL biopsies before and after seeding on porcine small intestinal submucosa (SIS-ECM). SIS-ECM has been used clinically for augmentation of the injured rotator cuff, Achilles tendon and other musculo-tendinous tissues. SISECM has been studied in the ACL location in a previous study and showed a decrease in tensile strength during the first 2-3 months, followed by an increase in strength to a value approximating that of the normal ACL at 12 months (Badylak et al., 1999). While such results are promising, SIS-ECM did not improve the strength of the remodelled ACL when compared to an autologous patellar tendon graft. Several studies have shown that SIS-ECM is a favourable substrate for attachment and proliferation of various cells types, including human endothelial, epidermal and fibroblastic cells (Badylak et al., 1998; Hodde et al., 2002; Lindberg and Badylak, 2001). However, to our knowledge, there are no studies in which fibroblasts derived from a ruptured ACL were seeded on SIS-ECM to create a tissue engineered ACL construct.

Traditional paraffin histology was performed to make comparisons of the cell and tissue organization. Comparisons of the cells were based on morphology, immunostaining, and gene expression of fibroblasts by RTPCR. Immunostaining and RT-PCR results were combined to study smooth muscle actin (SMA), the composition of the endogenous extracellular matrix (eECM), in particular collagen and elastic fibre organization. The interactions between the ACL fibroblasts and the surrounding eECM were evaluated by fibronectin and integrin expression patterns.

\section{Materials and Methods}

\section{Biopsy Sourcing and Treatment}

Human iACL and rACL biopsies were harvested from twelve patients during standard orthopaedic surgeries (total knee arthroplasty and ACL replacement, respectively) in order to complete a homogenous tissue bank (Table 1): 6 women and 6 men, 6 iACL and 6 rACL. Generally, total knee arthroplasty is performed on relatively old patients; therefore iACL came from patients with an average age of $66.8 \pm 15.9$ years. Conversely, rACL came from patients whose average age was $33.2 \pm 12.5$ years. This difference was considered during data analysis.

Immediately upon harvest, each biopsy was divided in 3 equal parts. The first part was fixed using 4\% paraformaldehyde or picroformol Bouin aqueous solution for histological and immunohistochemical analysis. The second part of the biopsy was preserved in an RNA stabilization reagent (RNAlater ${ }^{\mathrm{TM}}$, Qiagen, Courtaboeuf, France) for semi-quantitative RT-PCR. The third part was subjected to a validated decontamination protocol followed by comminution into small fragments and incubation in collagenase- 1 overnight at $37^{\circ} \mathrm{C}$ for cell extraction by enzymatic digestion. Extracted cells were grown to confluence in Dulbecco's minimal essential medium (DMEM) supplemented with $10 \%$ new born calf serum (NBCS), $0.5 \mathrm{mM}$ ascorbic acid 2 phosphate (AA2P), 1000 $\mathrm{UI} / \mathrm{ml}$ penicillin, $20 \mu \mathrm{g} / \mathrm{ml}$ gentamicin, $1 \mu \mathrm{g} / \mathrm{ml}$ amphotericin B. Cells were removed with trypsin-EDTA for subculture and used within passage 3 .

\section{Preparation of SIS-ECM}

Porcine small intestine was harvested from market weight pigs ( 110-130 kg) immediately after euthanasia. The tissue was rinsed and mechanically delaminated to remove the tunica muscularis externa (abluminal side) and the majority of the tunica mucosa above the muscularis mucosae (luminal side). The remaining tunica submucosa and basilar portion of the tunica mucosa consisted of ECM and the constituent cells. The SIS-ECM was then disinfected and decellularized in a $0.1 \%$ peracetic acid/ $4 \%$ ethanol solution followed by two rinses each in phosphate buffered saline (PBS) and deionised water. This process yielded a sheet of acellular SIS-ECM material that was then freeze-dried and terminally sterilized with ethylene oxide. The thickness of the sheets was approximately $50-100 \mu \mathrm{m}$.

Table 1: Tissue bank completed for the comparative study.

\begin{tabular}{c|c|c|c}
\hline ACL-Biopsy & Patient's age & Patient's gender & Pathology \\
\hline \multirow{5}{*}{ intact } & 38 & male & post-traumatic OA \\
& 60 & male & degenerative OA \\
& 70 & female & degenerative OA \\
& 74 & female & degenerative OA \\
& 78 & female & degenerative OA \\
& 81 & male & degenerative OA \\
\hline \multirow{6}{*}{ ruptured } & 19 & female & traumatic rupture \\
& 23 & female & traumatic rupture \\
& 28 & female & traumatic rupture \\
& 33 & male & traumatic rupture \\
& 46 & male & traumatic rupture \\
& 50 & male & traumatic rupture \\
\hline
\end{tabular}


a. culture ring

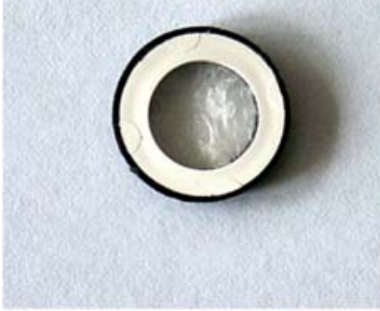

Figure 1: Culture conditions. (a) Culture rings used to maintain the SIS-ECM under tension during the culture process. (b) The culture chamber where the cellular constructs of a same donor were cultivated.

(c)

Schematic of the culture chamber in perfusion.

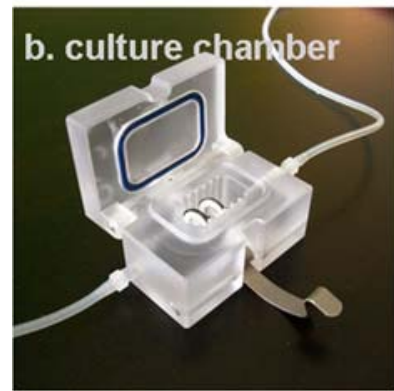

\section{c. culture in perfusion}

\section{Cell seeding on SIS-ECM and optimization of the culture parameters}

All the testing combinations were conducted with the cells isolated from the ACL of the same donor. At the moment of seeding, SIS-ECM was used either in its dehydrated state or hydrated through 24 hours of incubation in culture medium at $37^{\circ} \mathrm{C}, 95 \%$ of humidity. During the culture process, the SIS-ECM was either left under free floating conditions or subjected to static tension using culture rings to prevent its retraction by the cells. In order to do this, circular pieces of the SIS-ECM scaffold were cut from the original sheet with a $13 \mathrm{~mm}$ diameter biopsy punch under sterile conditions. The circular pieces were then placed into dishes under free floating conditions or under static tension imposed with the use of two interlocking plastic rings (Fig. 1a). Different ACL fibroblasts suspensions were prepared with cell concentrations ranging from $5 \times 10^{4}$ to $1 \times 10^{6}$ cells per $\mathrm{ml}$, then used to seed the pieces of SISECM at densities ranging from $5 \times 10^{4}$ to $1 \times 10^{6}$ cells per $\mathrm{cm}^{2}$ (constant volume). The seeded disks were left for 1 hour in an incubator at $37^{\circ} \mathrm{C}, 5 \% \mathrm{CO}_{2}$ and $95 \%$ humidity for initial cell adhesion. Then the disks were gently immersed in culture medium overnight to allow adequate time for the cells to attach more strongly. The disks were finally kept in static culture conditions (culture medium was changed every second day) or in a perfused system for 3 days, 1 week, 2 weeks and 3 weeks, using a buffered medium DMEM/F-12 1:1 with 2.5 mM L-Glutamine and 15 mM HEPES Buffer, supplemented with $10 \%$ NBCS, $0.5 \mathrm{mM}$ AA2P, $1000 \mathrm{UI} / \mathrm{ml}$ penicillin, $20 \mu \mathrm{g} / \mathrm{mlgentamicin}$ and $1 \mu \mathrm{g} / \mathrm{ml}$ amphotericin B.

For the perfused system, two sterile bags $\left(\right.$ Flexboy ${ }^{\circledR}$, Sartorius Stedim, Göttingen, Germany) for the culture media, and a culture chamber containing the rings with the cell constructs were prepared. The first bag, containing enough fresh medium for a whole week, was maintained at $4^{\circ} \mathrm{C}$ in a fridge, whereas the culture chamber and the second bag collecting the depleted medium were both placed in the incubator at $37^{\circ} \mathrm{C}$. The three modules were connected with silicon tubing and the flow could be adjusted thanks to a peristaltic pump. Due to the slow flow rate, the fresh medium heated to $20^{\circ} \mathrm{C}$ in its silicon tubing (40-50 $\mathrm{cm}$ long) during transport between the fridge and the incubator, and then to $37^{\circ} \mathrm{C}$ during transport $(80-100$ $\mathrm{cm}$ ) between the incubator wall and the culture chamber (Fig. 1).

\section{Scanning Electron Microscopy (SEM)}

For SEM analysis, samples were first fixed with $2.5 \%$ glutaraldehyde, then immersed in a $1 \%$ osmium tetroxide solution in $0.1 \mathrm{M}$ sodium cacodylate buffer. The samples were dehydrated in a graded ethanol series. Finally, the dehydrated samples were placed in a critical point dryer, mounted and sputtered with gold and examined by SEM (Leica S440; Leica, Wetzlar, Germany). Images were scanned on a computerized digital imaging system.

\section{Histology and Immunohistochemistry}

Specimens for histologic evaluation were first fixed in $4 \%$ paraformaldehyde, or in Bouin's picroformol aqueous solution. After fixation, biopsies and cellular constructs were paraffin embedded and $5 \mu \mathrm{m}$ sections were cut. Masson's trichrome staining (HT15, Sigma-Aldrich, St. Louis, MO, USA) of deparaffinized sections was used for the study of collagen fibres and connective tissue cells.

Immunohistochemical staining was conducted using the ready-to-use peroxidase-based EnVision ${ }^{\mathrm{TM}}$ system (K4006 K4010, Dakocytomation). Sections were deparaffinized and antigen retrieval was performed using either citrate buffer or hyaluronidase, according to primary antibody specifications. Non-specific sites were blocked with normal horse serum in a PBS 3\% bovine serum albumin solution. Diluted primary antibody solutions were applied overnight at room temperature. The following primary antibodies were used: Mouse monoclonal antihuman smooth muscle actin (Clone 1A4), (M0851, Dakocytomation, Glostrup, Denmark); Mouse monoclonal anti-human CD29 (integrin $\beta$-1) Ab-3 (Clone 7F10), (\#MS1089-S, Labvision Neomarkers, Fremont, CA, USA); Mouse monoclonal anti-human Integrin $\beta 3$ (Y2/51), (sc- 
20058, Santa Cruz Biotechnology, Santa Cruz, CA, USA); Mouse monoclonal anti-human integrin $\alpha 1$ I domain, (VMA1973, Abcys S.A., Paris, France); Mouse monoclonal anti-human integrin $\alpha \mathrm{V}$ subunit (CD51), (MAB1219, R\&D Systems, Minneapolis, MN, USA); Mouse monoclonal anti-human Fibrillin-1 Ab-2 (Clone 12A5.18), (\#MS-232-P1, Labvision Neomarkers); Rabbit polyclonal anti-human fibronectin, (24911, Novotec); Rabbit polyclonal anti-human collagen Type I, (20111, Novotec, Saint Martin La Garenne, France); Rabbit polyclonal anti-human elastin, (25011, Novotec); Rabbit polyclonal anti-human LOXL antibody was kindly provided by Dr. Pascal Sommer (IBDM, CNRS-UCBL, Lyon, France). Endogenous peroxidases were inhibited with a ready to use blocking reagent included in the manufacturer's kit, containing hydrogen peroxide and $0.031 \mathrm{~mol} / \mathrm{L}$ sodium azide. The secondary antibody was applied for $45 \mathrm{~min}$. A DAB + substrate-chromogen solution was applied to detect the signal. The slides were counterstained with Mayer's hematoxylin before mounting and coverslipping with an aqueous-based medium.

\section{RT-PCR}

Specimens to be used for RNA isolation and semiquantitative RT-PCR applications were stored in RNAlater $^{\mathrm{TM}}$ (Qiagen). At the beginning of the assay, samples were first immersed in an RLT lysis buffer (Qiagen). An Ultra-Turrax homogenizer was used to mechanically crush the samples. Proteinase K (Qiagen) was added to the lysis solutions to complete the tissue digestion. RNA extraction was conducted with the RNeasy ${ }^{\circledR}$ system (Qiagen) and the concentration was determined by measuring the absorbance at $260 \mathrm{~nm}$. Messenger RNA (mRNA) of interest were amplified by semi-quantitative RT-PCR (35 cycles), using the specific primers mentioned in Table 2. Amplicons were separated by electrophoresis using $1.5 \%$ agarose gels. The gels were immersed in a bath of SYBR ${ }^{\circledR}$ Green 1 (BMA, Rockland, ME, USA) for nucleic acid staining and analyzed by adapted software. The results were expressed as percentages compared to the expression of a housekeeping gene, the $28 \mathrm{~S}$ ribosomal RNA, $\pm \mathrm{SD}$.

\section{Statistics}

Statistical analyses were performed with the Student's $t$ test. Differences were considered significant at a $p$ value $<0.05$ (two-tailed).

\section{Results}

\section{Cell seeding on SIS-ECM and optimization of the culture parameters}

SEM images of preliminary seeding assays showed that fibroblasts from ACL biopsies could attach and spread on both, the more fibrillar abluminal surface and the smoother luminal surface of the SIS-ECM (Fig. 2a and 2b). Cells could migrate into the scaffold from the abluminal side due to the loose fibrillar architecture; therefore, this side was chosen for all subsequent seeding experiments.

At a high seeding density (up to $1 \times 10^{6}$ cells per $\mathrm{cm}^{2}$ ), fibroblasts covered totally the seeded surface by 1 to 3 days and formed a continuous cellular layer on the abluminal side of the scaffold. The samples seeded with the lowest cell density $\left(5 \times 10^{4}\right.$ per $\left.\mathrm{cm}^{2}\right)$ reached the same state of colonization after one week. On the samples seeded at a higher density, the cell density seemed to decrease inside the newly formed tissue layer by 1 week, as new endogenous ECM (eECM) was produced. After 2 weeks, the samples seeded at the lowest cell density displayed only a partial colonization of the cavities within the scaffold, whereas the samples densely seeded showed full colonization. At the same time point, the endogenous tissue layer existing on the abluminal side of the samples seeded at the highest density was strongly organized, parallel to the surface of the SIS-ECM (Fig. 2c).

Extensive contraction of the scaffold was observed for the constructs under free floating conditions at all the tested

Table 2: Human primer sequences used for semi-quantitative RT-PCR.

\begin{tabular}{c|c|c|c}
\hline Marker & Forward primer & Reverse primer & $\begin{array}{c}\text { Amplicon } \\
\text { (bp) }\end{array}$ \\
\hline col-I & GGACACAATGGATTGCAAGG & TAACCACTGCTCCACTCTGG & 461 \\
SMA & CCGGGAGAAAATGACTCAAA & GAAGGAATAGCCACGCTCAG & 256 \\
eln & GTATATACCCAGGTGGCGTG & CGAACTTTGCTGCTGCTTTAG & 357 \\
fbn1 & CTGCTTCCTGAGGTACGAGG & TGCACTTAAAGCTGCCAATG & 290 \\
fbln3 & AATTATCATGGCGGCTTCCG & CTTAACACAGAGCTTGTGCGG & 395 \\
fbln5 & AACCTGCGTCAACACCTACG & AGATAAGGCTCCTCACAGCG & 318 \\
LOXL & GACTTCGGCAACCTCAACC & TGTTGCAGAAACGTAGCGAC & 222 \\
$\alpha 1^{*}$ & GGAACAGAGAAGGAGGAGC & CGGTAAGATTAAAGTCCAACG & 799 \\
$\alpha 3^{*}$ & CAGAGGACCAAGGAAACC & TTGTAAGCAAAGCACAGC & 775 \\
$\alpha 5^{*}$ & GCAGAAGCAAAAGGGAGG & GCAAAGTAGTCACAGCTCAGG & 517 \\
$\alpha 9^{*}$ & GGCCAAAAAGGAGAAGG & GGAAACATTGAAGGACACG & 478 \\
$\alpha 10^{*}$ & AGAAAACACAGCCCAGACC & TGAACCAGCCTCAATAGTCC & 435 \\
$\alpha 11^{*}$ & GGAAAGGAGCCAAGAAGG & AGCAGGACATCAGTCACG & 721 \\
$\alpha \mathrm{V}^{*}$ & AAAGCGAACACGACCCAGC & GCCGTCACCATTGAAGTCTCC & 582 \\
$\beta 1^{*}$ & CAAAGGAACAGCAGAGAAGC & GTGGAAAACACCAGCAGC & 537 \\
$\beta 3^{*}$ & CAGAGGAAGGGACACCAAGC & TCACAAGGCAGCCAAGAGG & 673 \\
$\beta 5^{*}$ & AGGCACCACAGAGAAGACC & CAAACACGGACAGGAGAGG & 498 \\
$28 \mathrm{~S}$ & GCCTAGCAGCCGACTTAGAA & TAGGGACAGTGGGAATCTCG & 254 \\
\hline
\end{tabular}

* (Palaiologou et al., 2001). 
seeding densities, but the rate of contraction depended on the cell seeding density. Contraction occurred generally after 1 week for the samples seeded with $4 \times 10^{5}$ cells per $\mathrm{cm}^{2}$ or more and after 2 weeks or later for the samples seeded at a density of $2 \times 10^{5}$ cells per $\mathrm{cm}^{2}$ or less. Contraction of the scaffold was prevented by using interlocking rings. The addition of media perfusion accelerated the proliferation regardless of the seeding density. Later, when the cellular layer reached a certain thickness, perfusion seemed to promote eECM synthesis.

The optimal and most reproducible results were obtained with a seeding density of $2 \times 10^{5}$ cells per $\mathrm{cm}^{2}$ on SIS-ECM under tension and grown for 1 to 3 weeks under perfusion $(5 \mathrm{ml} / \mathrm{h})$. Under these conditions, the SIS-ECM seeded with ACL fibroblasts (regardless of iACL or rACL source) displayed histological characteristics similar to those of an iACL biopsy with regard to tissue organization and cell morphology, although the cell and collagen densities were different. As shown in Figure 3, an iACL biopsy and the SIS-ECM seeded with ACL fibroblasts both showed longitudinally oriented collagenous tissue containing elongated cells. However, the eECM of the seeded SIS-ECM construct remained substantially less dense than that of the intact ligament. The cellular construct also displayed a highly cellular layer at its surface, which is reminiscent of the organization of the epiligament, a thin envelope covering the iACL (Fig. 3).

\section{Cell phenotype in biopsies and SIS-ECM cell constructs}

Immunostaining for smooth muscle actin (SMA) showed very few SMA positive cells in the iACL, except cells located in the muscular layer of blood vessels (Fig. 4a). Within the rACL, SMA positive cells were widely distributed throughout the specimens (Fig. 4b). When fibroblasts isolated from iACL or rACL were seeded and grown on SIS-ECM, both expressed SMA and there was less difference in the synthesis of SMA between the cellular constructs cultured with each cell type as compared to the original biopsies (Fig. 4c and 4d). This finding was independent of the donors' age. In addition, the SMA positive cells were primarily located within or adjacent to the SIS-ECM scaffold. RT-PCR results confirmed that there was a difference in SMA expression between cells derived from iACL and rACL, with fibroblasts from a rACL showing nearly double the expression of SMA compared to iACL cells. Both cell populations express SMA at similar levels after 3 weeks in culture (Fig. 4e).

ACL fibroblasts positively stained for integrin subunits $\alpha \mathrm{V}, \beta 1, \beta 3$, and were detected in intact and ruptured biopsies. In both groups, sections contained 70 to $90 \%$ of cells positive for $\alpha \mathrm{V}$ and $\beta 1$ (Fig. 5a and 5d) and about $20 \%$ for $\beta 3$ (Fig. $5 \mathrm{~g}$ ). The only positive staining for the $\alpha 1$ subunit was shown in the luminal layer of some vessels within the biopsies, probably on endothelial cells (not shown). RT-PCR results showed that cells extracted from iACL expressed $\alpha \mathrm{V}$ more strongly, whereas the expression of $\beta 1$ was higher for rACL fibroblasts (Fig. 5c and 5f). After one week in culture on SIS-ECM, greater than $90 \%$ of all fibroblasts were stained positive for $\alpha \mathrm{V}$ and $\beta 1$
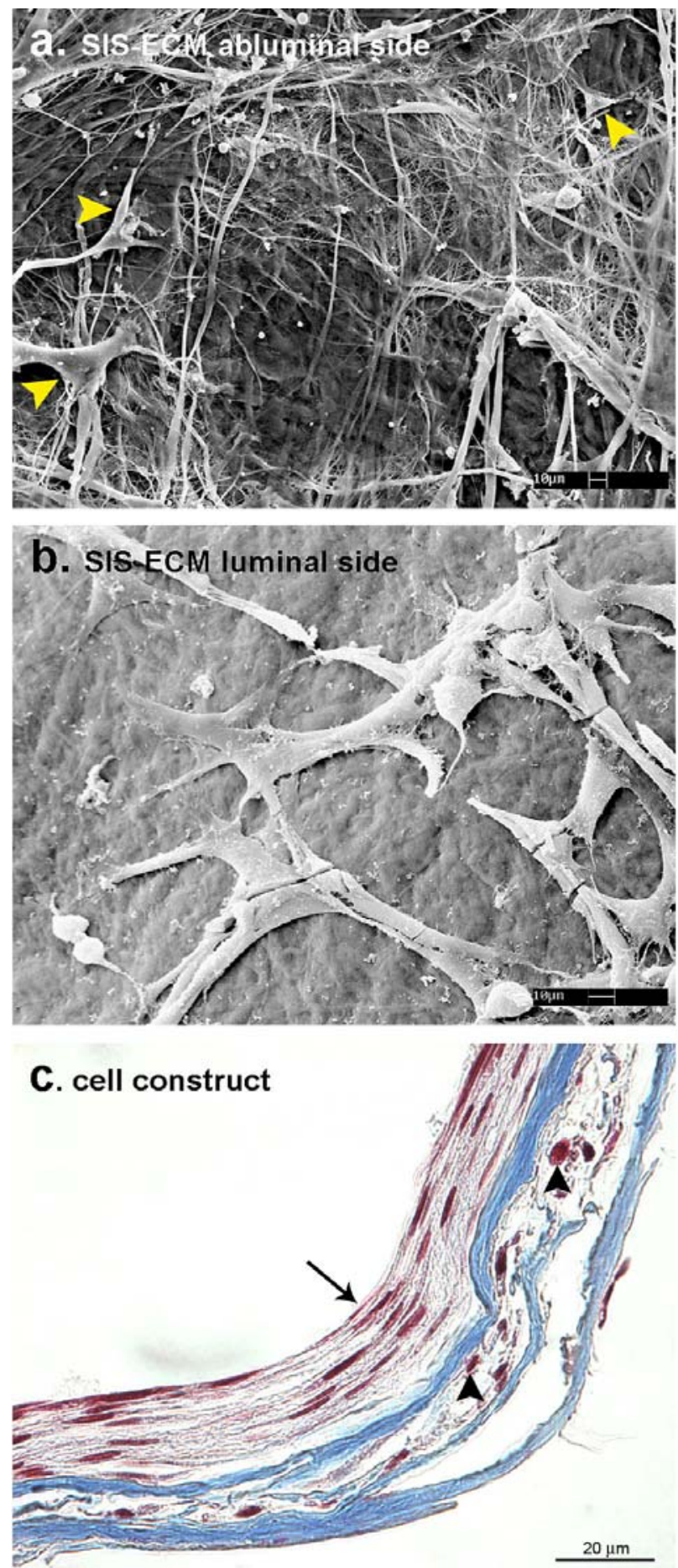

Figure 2: ACL-cell seeding on SIS-ECM and cell construct formation. (a) SIS-ECM Abluminal side is made of a loose fibrous structure - on which ACL cells (yellow arrowheads) can easily attach - and displays accesses to the scaffold inner layers. (b) SIS-ECM Luminal side is characterized by a plane surface - dense and relatively smooth - on which ACL cells are spread out. (SEM, 3 days of culture). (c) Section of a typical 2 weeks SIS-ECM cell construct. Cells proliferated and formed a layer of dense endogenous tissue on the seeded abluminal surface (arrow), but a few cells could migrate and colonize some deeper cavities (arrowheads). (Masson's trichrome). 

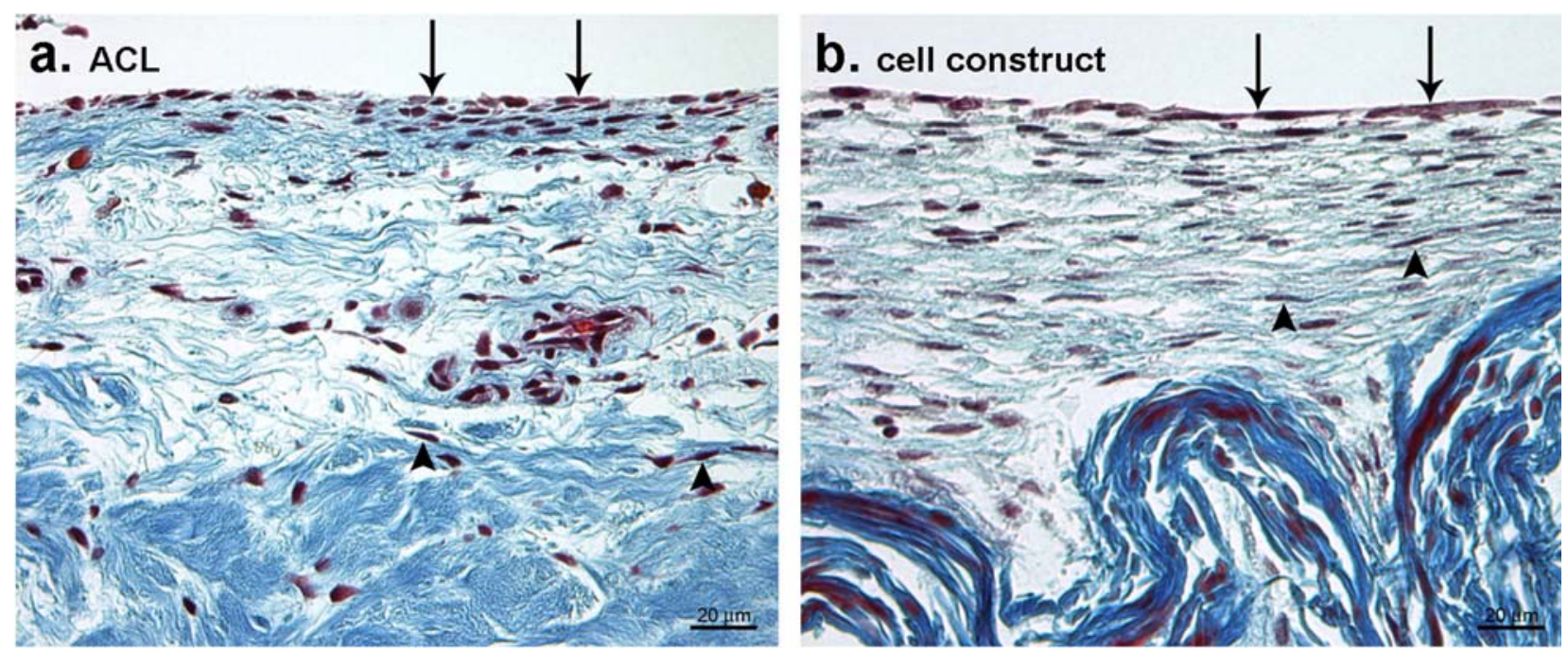

Figure 3: Native iACL and SIS-ECM cell construct. Comparative histology between iACL and the SIS-ECM ACL cell construct (rACL extracted, after 3 weeks in culture). In spite of a substantial difference in ECM density, both tissues displayed a longitudinal organisation and contained oriented elongated cells (arrowheads). The figure also illustrates how the highly cellular epiligament on the iACL was reproduced in vitro by a particularly dense cellular layer on top of the cellular construct (arrows) (Masson's trichrome).

subunits, regardless of the source of the cells, following a expression pattern similar to those observed in the biopsies (Fig. $5 \mathrm{~b}$ and $5 \mathrm{e}$ ). Up to $50 \%$ of the cells were shown to be positive for the $\beta 3$ subunit, which was greater than in native tissues (Fig. 5h). The gene expression of $\beta 1$ remained substantially higher for rACL cells, once seeded on the scaffold (Fig. 5f).

Additional RT-PCR data showed that all tested integrin subunits except $\alpha 3$ were expressed in the biopsies, although there were statistically significant differences for some of them between iACL and rACL fibroblasts (Fig. 6). The expressions of $\alpha 1$ and $\beta 5$ were significantly lower by rACL fibroblasts compared to fibroblasts isolated from iACL (Fig. 6a and 6f). When either group of cells was seeded on SIS-ECM, all tested subunits were also expressed with the exception of $\alpha 3$. Interestingly, no differences were observed for $\alpha 1$ and $\beta 5$ between iACL fibroblasts and rACL fibroblasts seeded on SIS-ECM at any time point. Only the expression of $\alpha 11$ was significantly greater for rACL fibroblasts as compared to iACL fibroblasts within SIS-ECM cellular constructs (Fig. 6e).

\section{ECM composition in biopsies and SIS-ECM cell constructs}

Collagen type I (Col-I) was similarly distributed throughout the iACL and rACL (Fig. 7a). There was no significant difference in the gene expression of Col-I between fibroblasts extracted from iACL and rACL (Fig. 7c). Immunostaining for fibronectin (FN) did not show any difference between iACL and $\mathrm{rACL}$, and showed a strong staining particularly around the cells included in the biopsies (Fig. 7d). Immunostaining results showed that Col-I and FN were also both widely distributed through the tissue in the eECM of the ACL fibroblast seeded SISECM constructs (Fig. 7b and 7e). Data obtained by RTPCR determined that col-I expression was significantly higher by rACL fibroblasts seeded on SIS-ECM after three weeks in culture (Fig. 7c). However, as it was previously mentioned in methods, this observation must be addressed together with the fact that cells isolated from $\mathrm{rACL}$ correspond to younger patients.

Immunostaining for elastin (Eln) showed a difference between biopsies correlated to the patients' age. ACL harvested from young patients contained a considerable amount of Eln fibres, whereas the biopsies harvested from older patients contained very few Eln fibres (Fig. 8a and $8 b)$. There was no difference detected between the Eln expression by ACL cells from young and old patients by RT-PCR, although gene expression does necessarily correlate to extracellular secretion of the protein. Contrary to the differences related to the patients' age, no differences were observed in the presence or expression of Eln with respect to whether the ACL was intact or ruptured (Fig. 8d). In both iACL SIS-ECM and rACL SIS-ECM cellular constructs, immunostaining revealed a complete absence of Eln after 3 weeks in culture (Fig. 8c) despite expression detected by RT-PCR. The native SIS-ECM was found to contain Eln by immunostaining.

With regard to the presence of other components of the elastic network in the biopsies, our data suggest that Fibrillin-1 (Fbn1) is also widely distributed in both iACL and rACL (Fig. 9a). Most of the cells found in the biopsies were positively stained for lysyl oxidase-like 1 (LOXL), which is involved in the cross linking of the elastic fibres. However, no positive staining was detected in the ECM where LOXL is supposed to be active (Fig. 9d). RT-PCR results showed that the rupture of the ACL did not significantly alter the expression of these two elastic markers (Fig. 9c and 9f). Immunostaining demonstrated the presence of Fbn1 in the eECM, and LOXL in the vicinity of the fibroblasts in the ACL SIS-ECM cellular constructs (Fig. 9b and 9e), mimicking the pattern observed in the biopsies. RT-PCR data showed that both were also expressed in a similar way in the native tissues and in the 

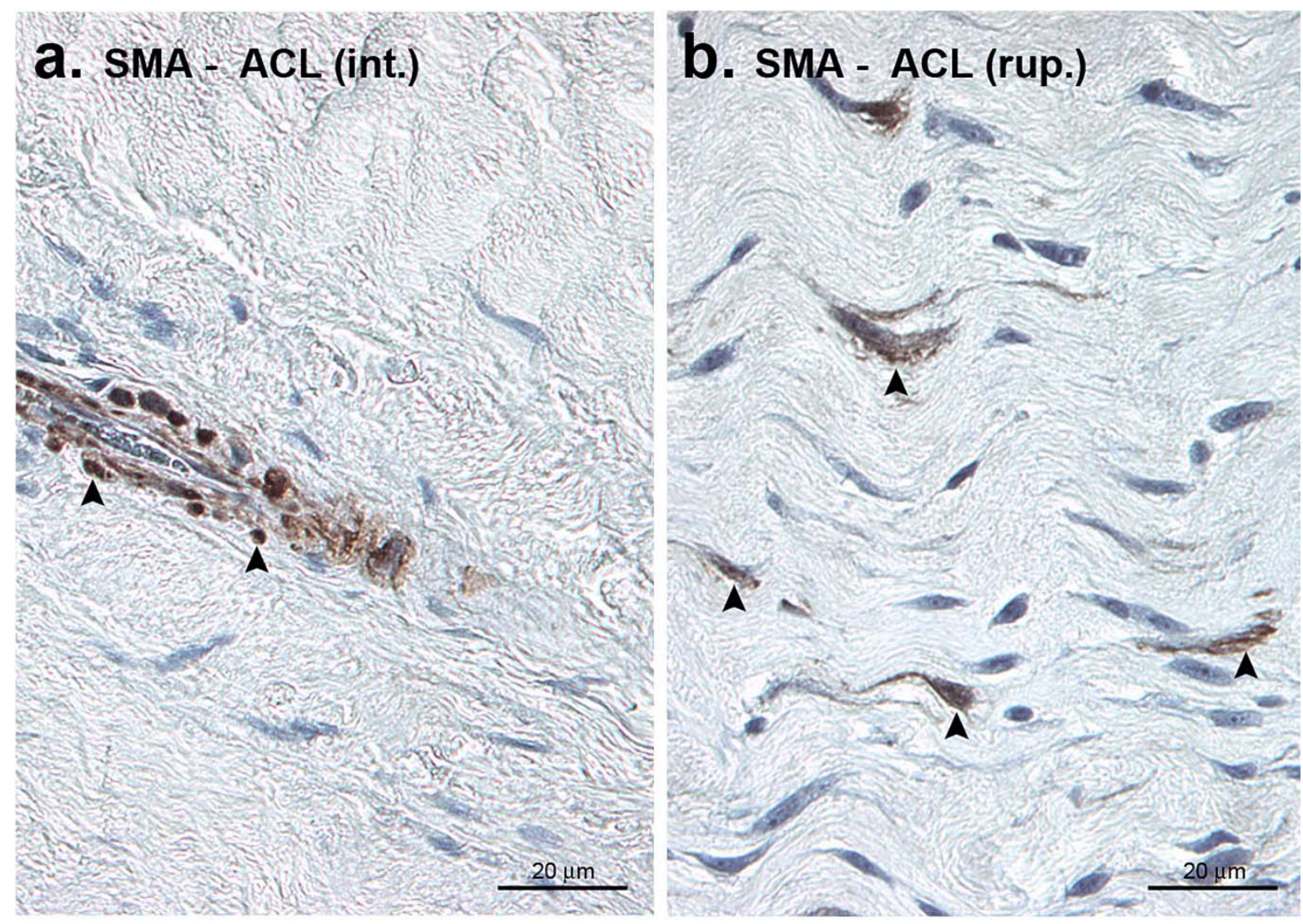

\section{SMA - cell construct (int.) d. SMA - cell construct (rup.)}
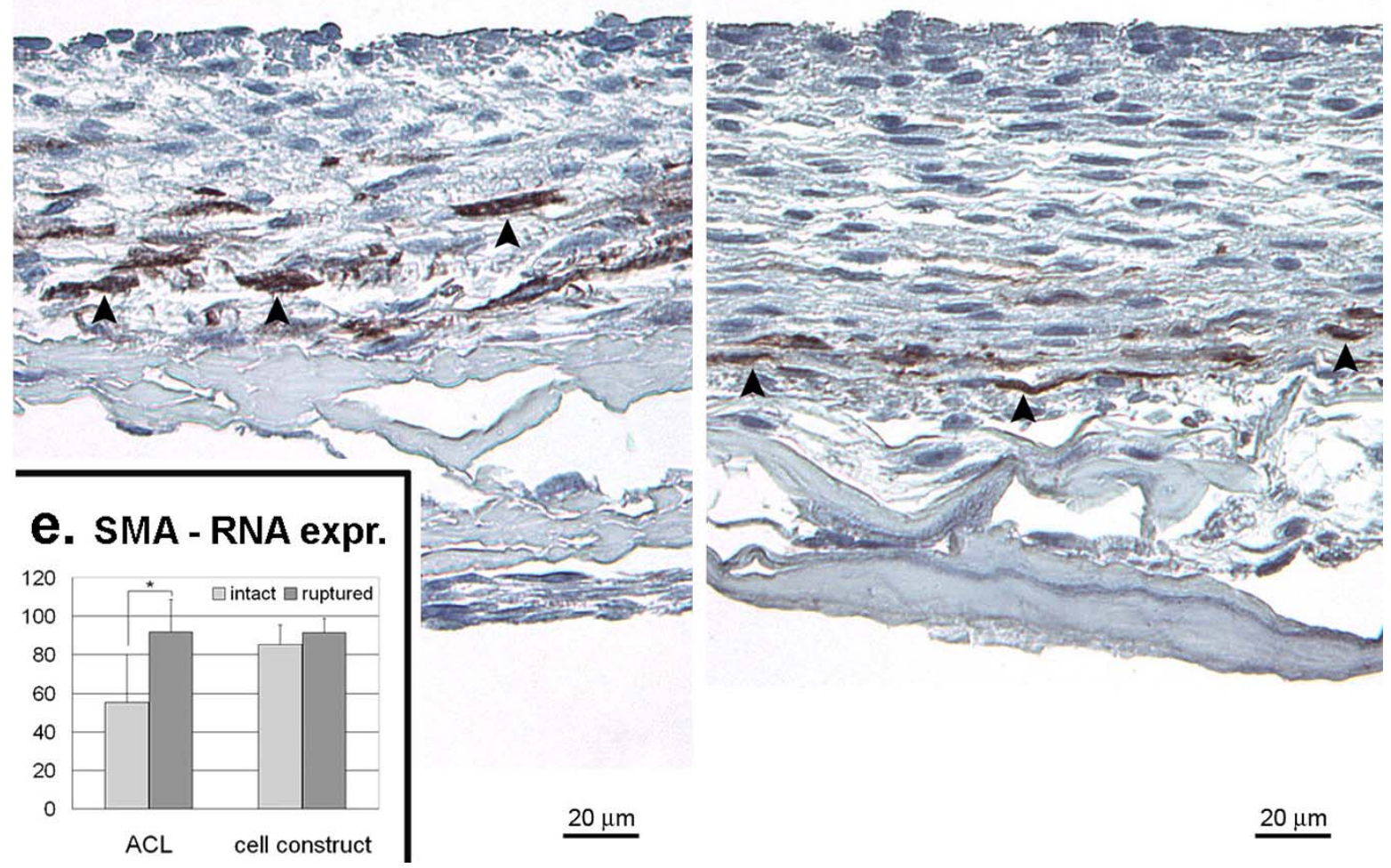

Figure 4: Cell phenotype: SMA. (a) Immunostaining directed against smooth muscle actin (SMA) shows that iACL contains very few fibroblasts positive for SMA (myofibroblasts). Positive smooth muscle cells can be detected in the outer layer of vascular structures. (b) In contrast, more SMA positive cells could be detected in the connective tissue of rACL. (c-d) After 3 weeks in culture on the SIS-ECM, several cells extracted from iACL and rACL biopsies synthesized SMA. In both types of constructs positive cells (arrowheads) were detected nearby or in contact with the tensioned SISECM scaffold. (e) Expression of SMA measured by semi-quantitative RT-PCR. Significantly ( $p<0.05$ indicated by an asterisk*) higher SMA expression in the cells from rACL biopsies, and equally high, but similar expressions in the two cell populations within the constructs after 3 weeks in culture. 


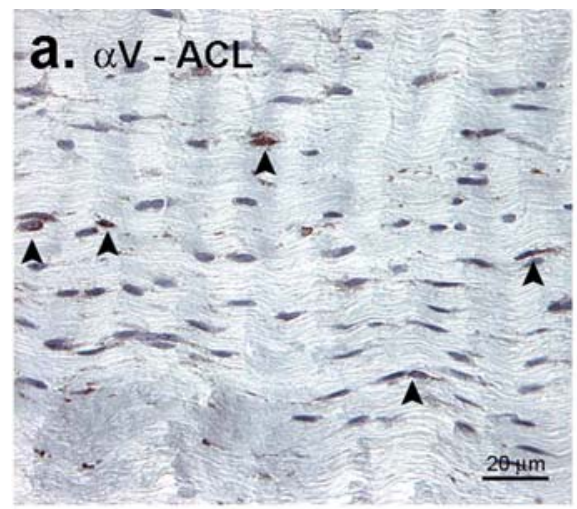

b. $\alpha \mathrm{V}$ - cell construct

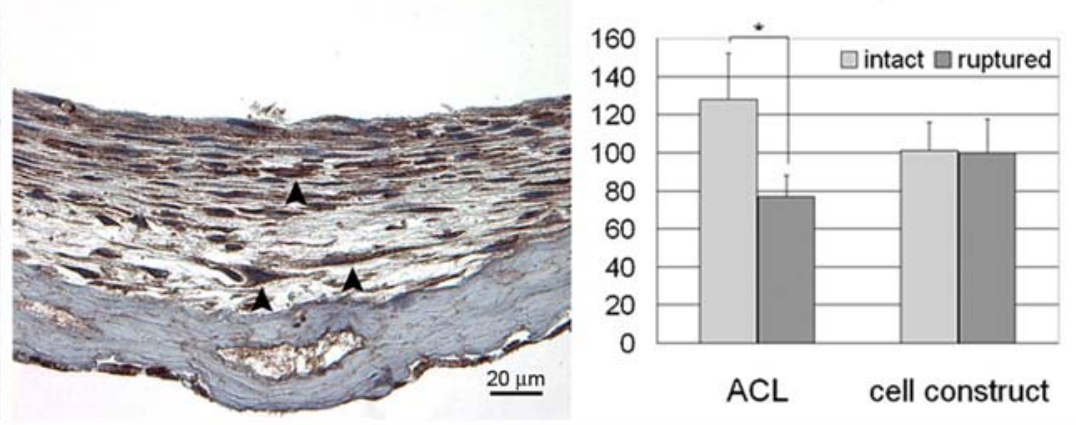

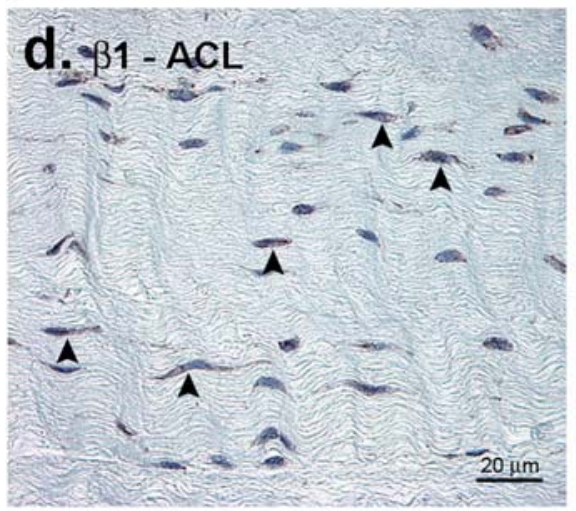

e. $\beta 1$ - cell construct

f. $\beta 1$ - RNA expr.
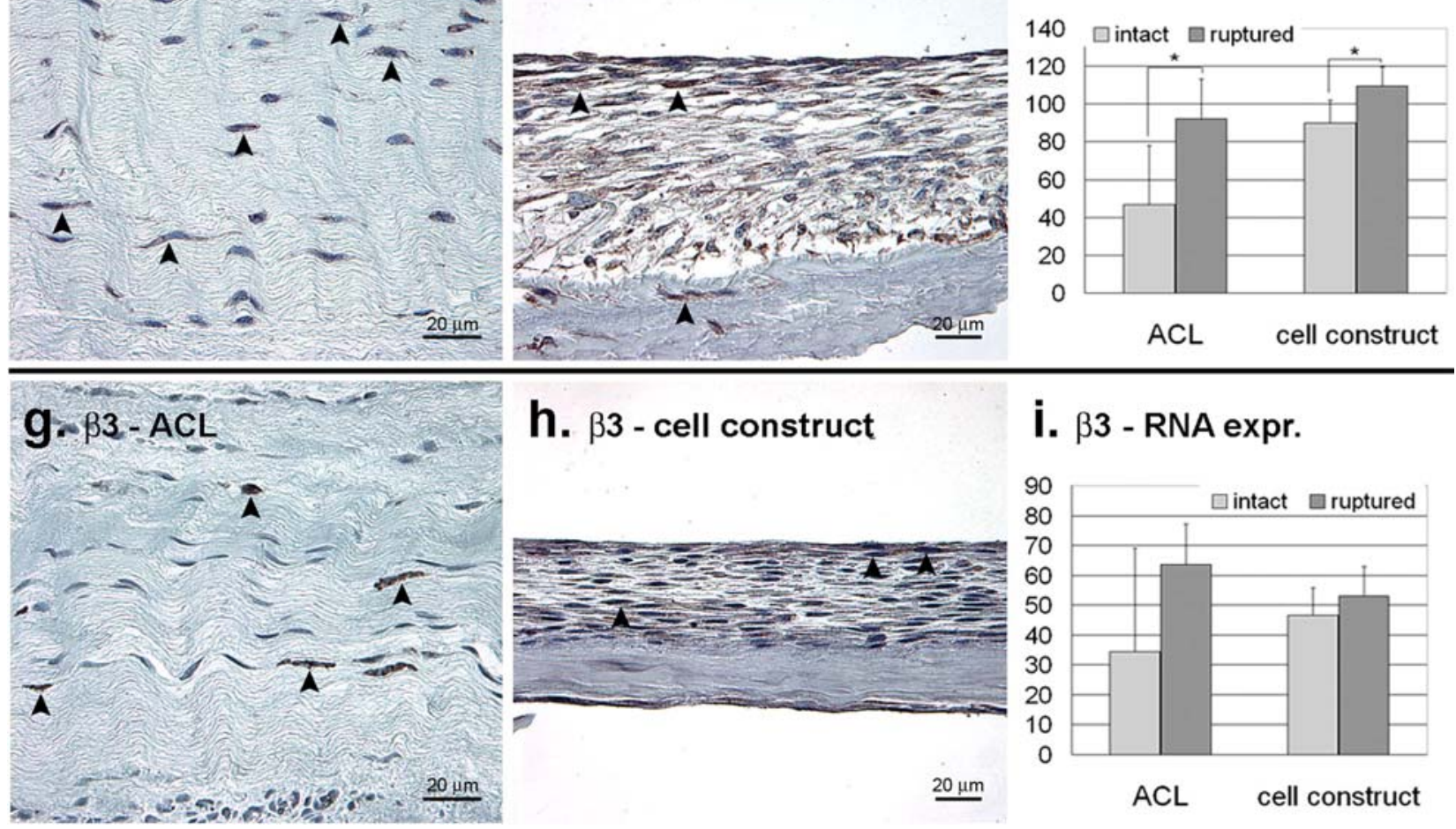

h. $\beta 3$ - cell construct

i. $\beta 3$ - RNA expr.
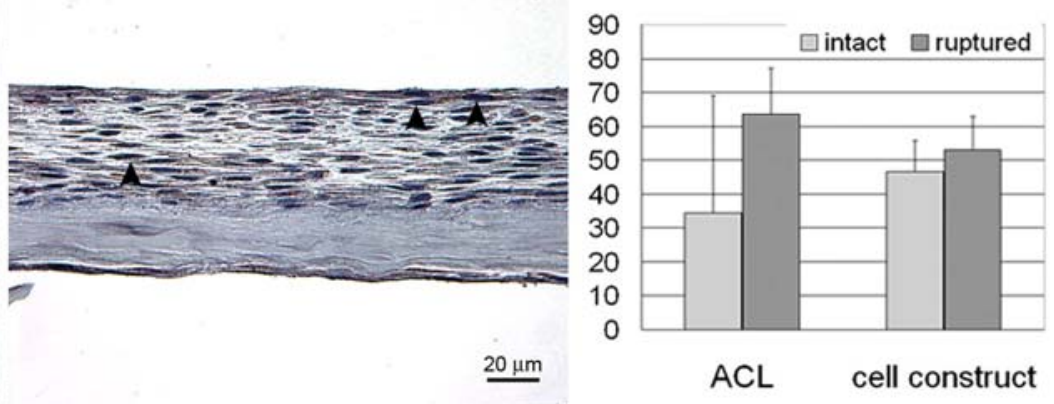

Figure 5: Cell adhesion: integrin subunits $\alpha \mathrm{V}, \beta 1$ and $\beta 3$ (a), (b), (d), (e), (g) and (h). Immunostaining showed that most of the cells were detected to be positive for $\beta 1$ and $\alpha \mathrm{V}$ and only a few of them for $\beta 3$ in the native tissues, whereas positive cells (arrowheads) for the 3 subunits were present throughout the cell constructs. $\mathrm{c}, \mathrm{f}$ and i. $\alpha \mathrm{V}, \beta 1$ and $\beta 3$ gene expression measured by RT-PCR tended to show that there were less differences between cell constructs seeded with iACL and rACL fibroblasts than between the original biopsies, although this was statistically significant only for $\alpha \mathrm{V}(p<0.05$, indicated by an asterisk *).

SIS-ECM cellular constructs (Fig. 9c and 9f). Fibulin-3 and 5 (fbln 3 and 5), two additional markers of the elastic network were similarly expressed in intact and ruptured biopsies. Once seeded on the scaffold, rACL fibroblasts displayed a higher fbln5 expression (Fig. 10).

\section{Discussion}

Fibroblasts derived from both the iACL and rACL were successfully seeded on SIS-ECM. The culture conditions were optimized by testing a large variety of cell densities ranging from $5 \times 10^{4}$ to $1 \times 10^{6}$ cells per $\mathrm{cm}^{2}$. The low seeding densities were investigated to promote cell-scaffold interactions rather than cell-cell interactions. The higher densities were tested to accelerate the colonization of the scaffold. The preliminary studies showed that the best results occurred when freeze-dried discs of SIS-ECM were seeded at $2 \times 10^{5}$ cells per $\mathrm{cm}^{2}$, gripped under tension with culture rings, and cultured under perfusion conditions. The SIS-ECM scaffolds seeded with ACL fibroblasts showed similar histological patterns to the iACL, in particular, the cellular constructs were longitudinally organized collagenous tissues containing elongated cells after 2 to 3 weeks of culture.

Combining immunohistochemical pictures and semiquantitative data measured by RT-PCR, the present study found differences in the molecular profiles of fibroblasts contained in iACL and rACL. SMA expression was significantly higher by fibroblasts from the rACL, which is consistent with previous findings (Murray et al., 2000; Murray and Spector, 1999; Spector, 2001). Intact ACL 

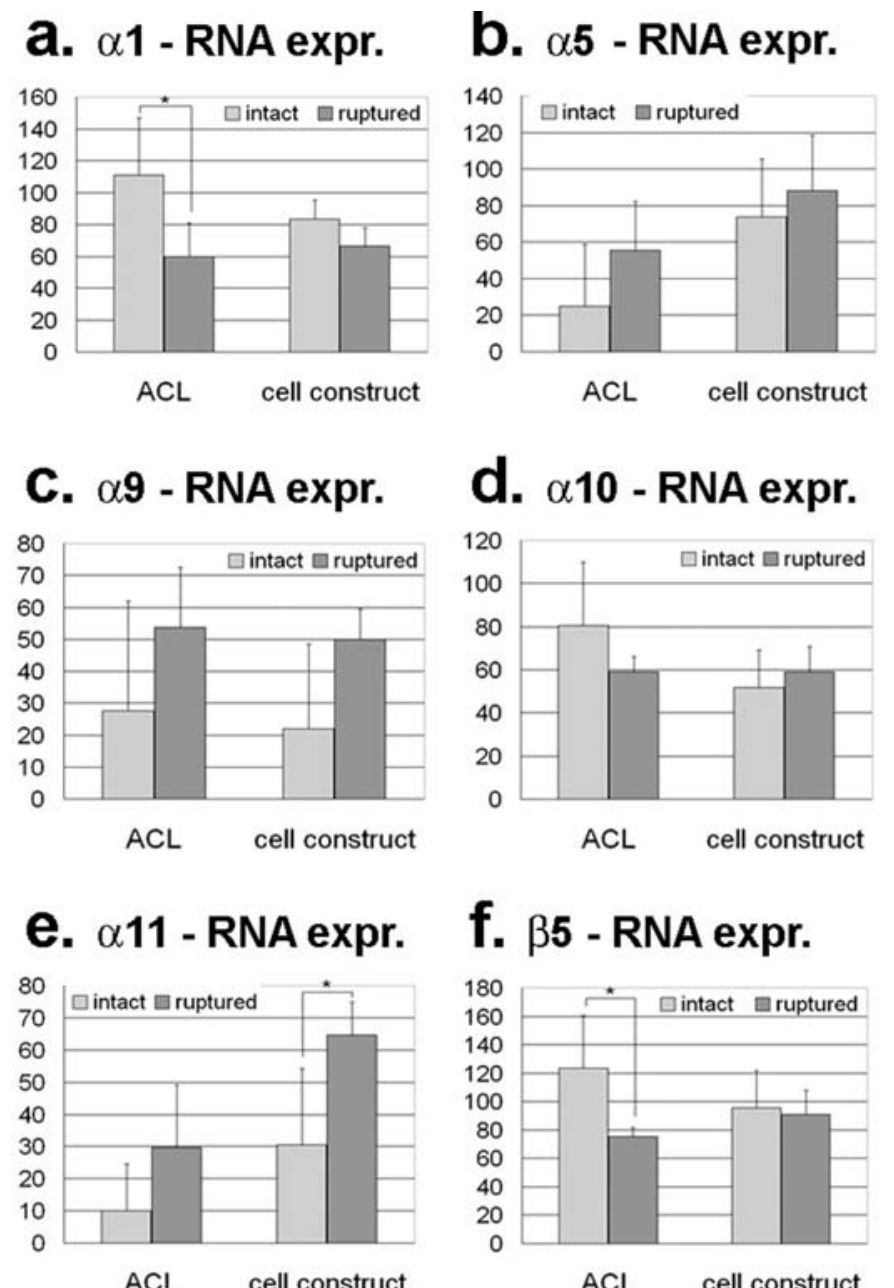

Figure 6: Cell adhesion: integrin subunits $\alpha 1, \alpha 5$, $\alpha 9, \alpha 10, \alpha 11$ and $\beta 5$. Gene expression measured by semi-quantitative RT-PCR for respective integrin subunits $\alpha 1, \alpha 5, \alpha 9, \alpha 10, \alpha 11$ and $\beta 5$. In spite of significant differences with regard to the expression

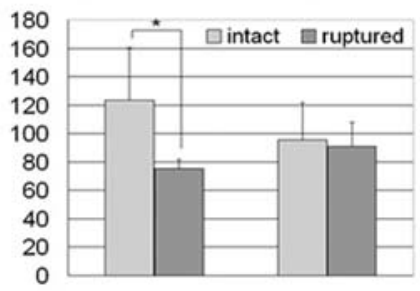
of $\alpha 1$ and $\beta 5$ between cells from iACL and rACL, the expressions were similar between the two populations within the cell constructs after 3 weeks in culture. Conversely, expression of $\alpha 11$ remained significantly different within the constructs seeded with the two cell populations. Significant $(p<0.05)$

$\mathrm{ACL} \quad$ cell construct

ACL cell construct differences are indicated by an asterisk $(*)$.

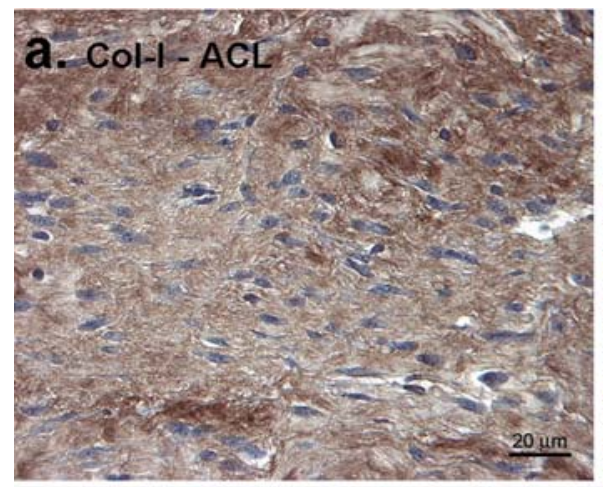

\section{b. Col-I - cell construct}

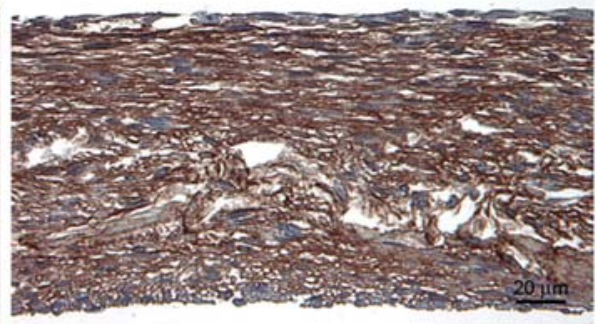

e. $\mathrm{FN}$ - cell construct

\section{Col-I - RNA expr.}

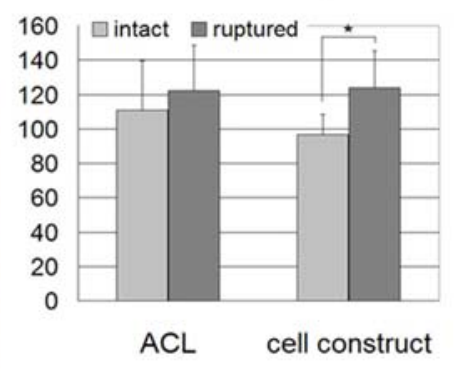

\section{d. FNEACL}
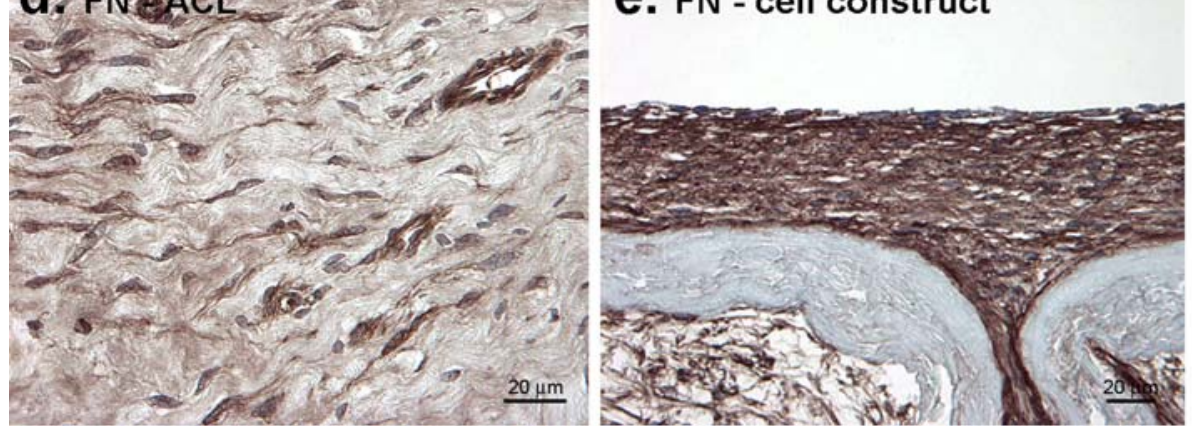

Figure 7: ECM, Col-I and FN. (a-b) Immunostaining directed against Col-I shows that both, intact and ruptured ACLs, and both respective cell constructs have an ECM which contains high amounts of Col-I. (c) Col-I gene expression in biopsies and SIS-ECM cell constructs measured by semi-quantitative RT-PCR. After 3 weeks in culture on the scaffold, cells extracted from rACL showed an expression of col-I significantly higher as compared to iACL fibroblasts. Significant $(p<0.05)$ differences are indicated by an asterisk (*). (d-e) While FN staining was widely and evenly distributed in the cell constructs, FN staining was particularly strong only close to the cells in the ACL biopsy. 


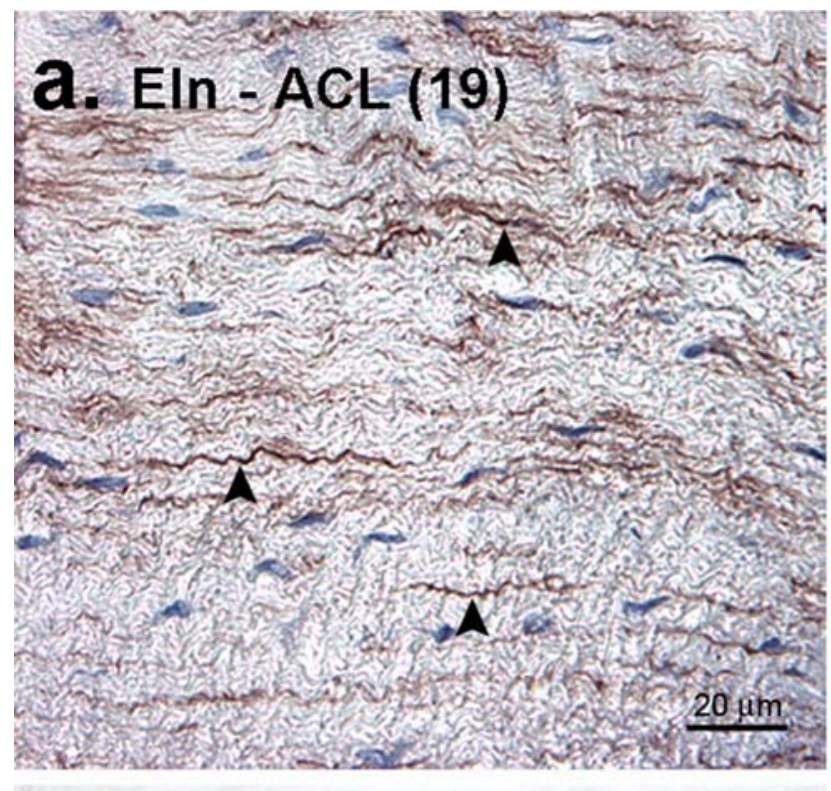

\section{EIn - cell constrüct}

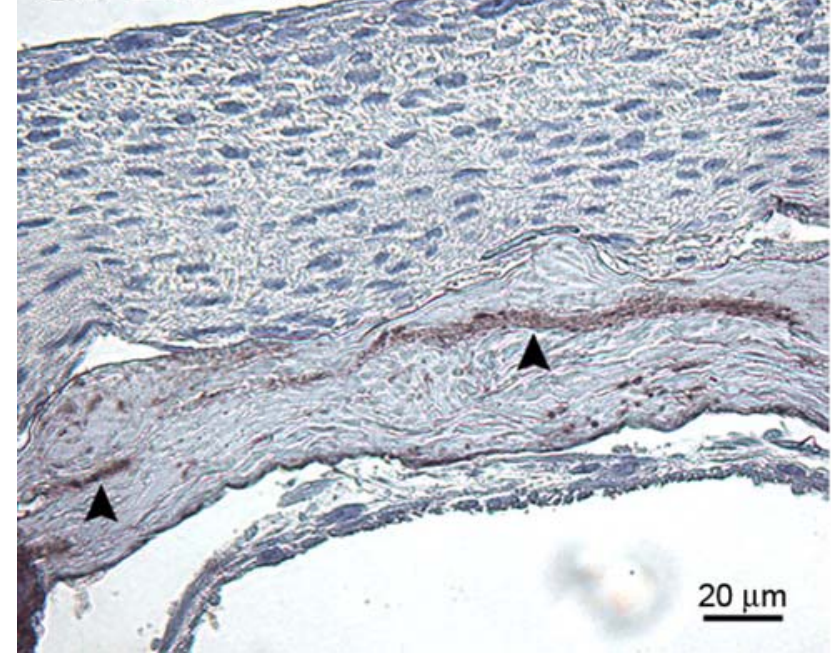

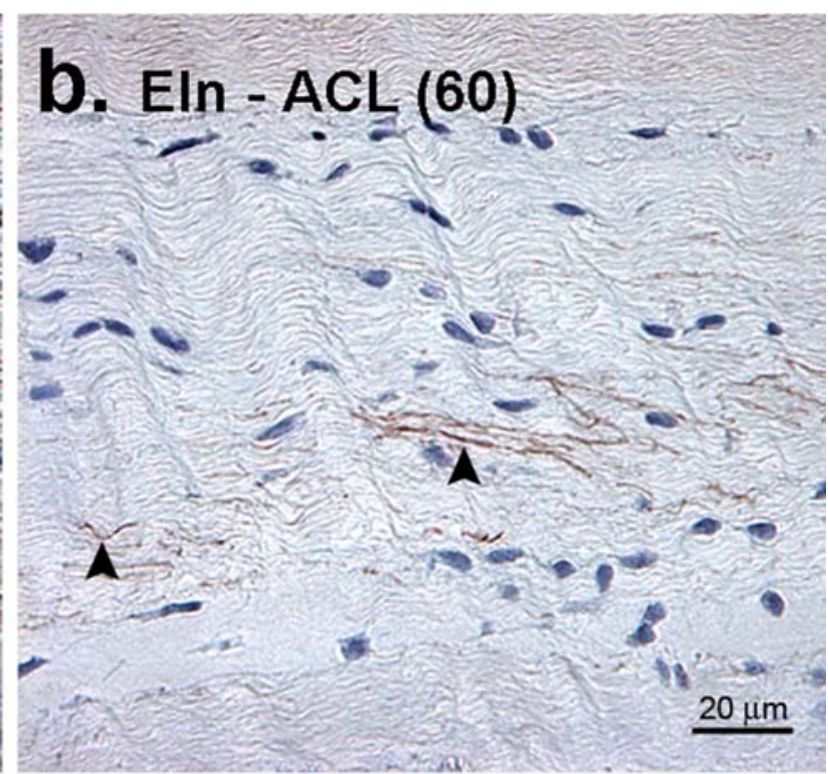

d. EIn - RNA expr.

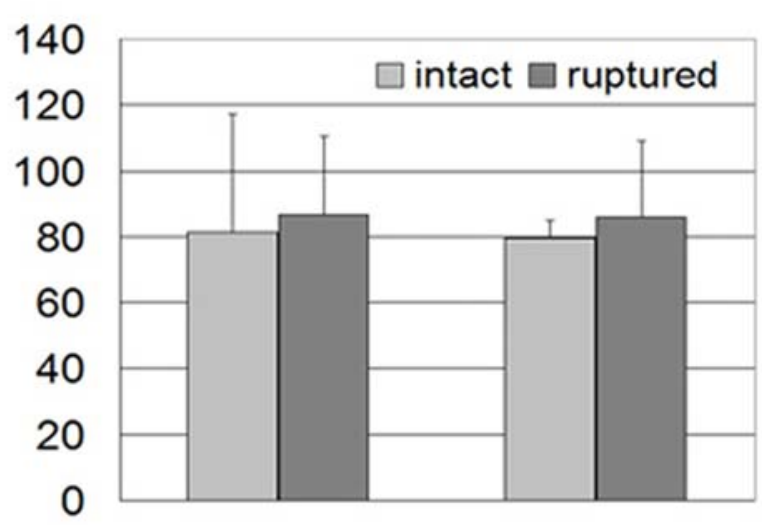

$\mathrm{ACL}$ cell construct

Figure 8: ECM, elastic network: Eln. (a-b) Immunostaining directed against Eln in biopsies from a 19 years old and a 60 years old patient show that the elastic fibres are fewer and much thinner in the biopsy of the older patient. (c) No positive staining for Eln was detected in the cell constructs, except in the scaffold (arrowheads). (d) RT-PCR data showed that there was no difference between both original biopsies and both cell constructs with regard to Eln expression.

naturally contained a small subpopulation of fibroblasts positive for SMA, whereas this population was substantially larger in rACL. These particular cells are named myofibroblasts. Their presence in the rACL is correlated to the wound healing process that occurs in the ligament after the rupture.

The expressions of the $\alpha 1, \alpha \mathrm{V}, \beta 1$, and $\beta 5$ integrin subunits were also statistically different between cells isolated from iACL and $\mathrm{rACL}$, with less expression of $\alpha 1$, $\alpha \mathrm{V}$ and $\beta 5$ and higher expression of $\beta 1$ by rACL cells. Integrins are responsible for interactions between cells and the ECM, and are involved in signal transduction in response to stimuli, such as mechanical loading. AbiEzzi et al. (1995) demonstrated that $\alpha 5, \alpha \mathrm{V}$ and $\beta 1$ expressions were increased in rabbit ACL during prolonged immobilization. Complete rupture leads necessarily to a stress-deprived state, and our results also showed that the complete integrin profile was substantially modified in human ruptured ACL.

Immunostaining showed that cells positive for integrin subunits $\alpha 1, \alpha \mathrm{V}, \beta 1$ and $\beta 3$ were similarly detected in both cellular constructs and in the native tissues, although significantly more $\beta 3$ positive cells were detected in the cell constructs. RT-PCR data showed that all subunits expressed in $\mathrm{AACL}$ and $\mathrm{rACL}$ were also expressed in cellular constructs. These results confirm that both iACL and $\mathrm{rACL}$ cells express integrin subunits $\alpha 1, \alpha 5, \alpha \mathrm{V}, \beta 1$, $\beta 3$, but not $\alpha 3$ (Bhargava et al., 1999; Gesink et al., 1992; McKean et al., 2004). ACL fibroblasts seeded on SIS-ECM also expressed $\alpha 9$, commonly described as a putative specific receptor for tenascin C, a macromolecule naturally present in the ECM of iACL (Yokosaki et al., 1998). Once seeded on SIS-ECM, ACL cells synthesized an endogenous ECM rich in Col-I and FN, similar to the iACL. These 



Figure 9: ECM, elastic network: Fbn1 and LOXL. (a-b) and (d-e) Immunostaining demonstrates that LOXL and Fbn1, two major components of the elastic network, are similarly synthesized in both original ACLs and both cell constructs. (c) and (f) Expression of fbn1 and LOXL measured by RT-PCR in AACL, rACL and the cell constructs after 3 weeks of culture did not show any significant difference.

results are likely related to the expression of integrin subunits. $\alpha \mathrm{V}, \beta 5$ and $\beta 3$ were all expressed in both iACL SIS-ECM and rACL SIS-ECM cellular constructs, and when bound together form specific receptors for $\mathrm{FN}(\alpha \mathrm{V} \beta 3$ and $\alpha \mathrm{V} \beta 5$ ) (Lowrie et al., 2004). $\alpha 10$ and $\beta 1$, which were also highly expressed, form specific receptors for collagens when bound together, or when bound to $\alpha 1(\alpha 1 \beta 1$ and $\alpha 10 \beta 1)$.

During in vitro culture, the expression profiles by iACL and rACL fibroblasts tended to be similar. SMA expression was the best illustration of this phenomenon, with equal and elevated expression showed by immunohistochemistry. After seeding the fibroblasts from each group onto SISECM, the number of SMA positive cells was comparable and close to that in the rACL. Moreover, the location of SMA positive cells within the ACL SIS-ECM cellular constructs tended to close proximity to the scaffold. The same result could also be observed by semi quantitative RT-PCR after 3 weeks in culture in cellular constructs seeded with both iACL and rACL. Myofibroblasts extracted from rACL may conserve the ability to express SMA, once seeded on SIS-ECM. However, since both ACL cell populations are concerned, we can assume that SMA expression in the cell constructs is most likely also due to the mechanical stress caused by the tensioned scaffold. Similar findings were observed for most of the integrin subunits, except for $\alpha 9$ and $\alpha 11$. In spite of significant differences in their native tissues, cells extracted from iACL and rACL progressively displayed comparable behaviour in vitro when seeded on SIS-ECM scaffold. The authors attempted to correlate the age of the patient and the expression of the different markers to see whether the

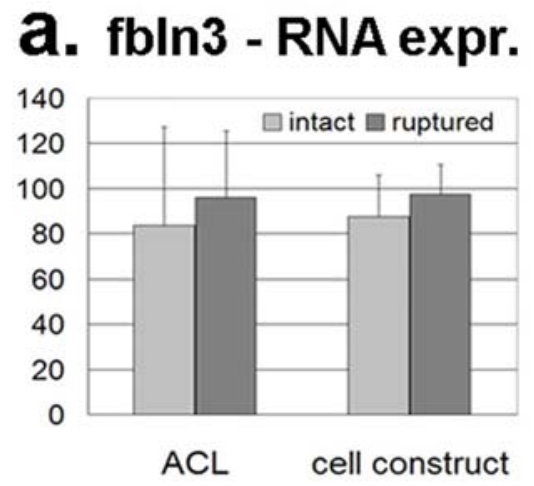

\section{b. fbln5 - RNA expr.}

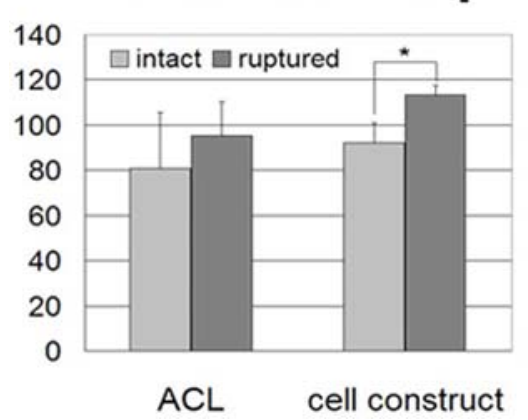

Figure 10: ECM, elastic network: Fbln3 and 5. Expression of fbln 3 and fbln 5 measured by RT-PCR in the native tissues and the cell constructs after 3 weeks in culture. Once seeded on SIS-ECM and after 3 weeks in culture, cells extracted from rACL showed an expression of fbln5 significantly higher than iACL cells. Significant $(p<0.05)$ differences are indicated by an asterisk (*). 
wide range of ages could explain this result, but no correlation could be found. This result may be due to dedifferentiation of the cells in vitro, or to the fact that any differences are minimal.

With regard to the elastic network, the biopsied ACL of older patients contained less elastic fibres than young patients and the fibres that were present were thinner. However, gene expression for Eln did not show the same variation related to the patients' age. This may be due to the fact that synthesis of elastic fibres is deficient in connective tissues of older patients. In such tissues, Eln can be synthesized but not bounded to the microfibrils, nor properly cross linked. In that case, the protein is present in the ECM under an amorphous unstable state easily degradable and hard to stain. In vitro, Eln expression was comparable by cells contained in the biopsies and ACL SIS-ECM cellular constructs throughout the culture period. However, no Eln was synthesized by ACL fibroblasts seeded on SIS-ECM. This result is not surprising since in vitro synthesis of Eln has rarely been reported. In a previous study, rACL cells were shown to be able to synthesize amorphous non-cross linked Eln in different culture conditions only after 6 weeks. Data concerning all the other tested components involved in elastic network were positive (Liu et al., 2004; Thomassin et al., 2005; Yanagisawa et al., 2002). The results showed that LOXL and Fbn1 had similar patterns of expression in the biopsies and the ACL SIS-ECM cellular constructs, independently of the cell origin. The molecular profiles were also similar for fbln 3 and fbln5.

In summary, this study shows that in spite of differences between ACL fibroblasts obtained from intact or ruptured ACL, those differences were minimized through in vitro culture of the cells on an SIS-ECM scaffold. The organization and composition of the seeded constructs suggest a potential application for ACL repair with SISECM as a substrate material. However, several aspects still have to be optimized, including cell attachment and penetration into the SIS-ECM scaffold, collagen density within the cellular layer. Indeed, although the organization of the newly formed collagen fibres within the ACL SISECM cellular constructs was similar to the iACL, the endogenous collagen seemed much less dense in the constructs as compared to the biopsies. This collagen produced by the seeded fibroblasts is crucial, since it is involved in the achievement of high mechanical properties. Although the present study does not include any mechanical characterization of the ACL SIS-ECM cellular construct, it can be assumed that the construct thickness and thus mechanical resistance will have to be improved to eventually provide an ACL substitute with adequate strength. An option to increase the primary mechanical strength of the scaffold is to use a multilaminate form of SIS-ECM. Mechanical stimulation is a possibility to increase the secondary strength of the whole construct, and this has been shown to influence cell behaviour, particularly with regard to collagen synthesis and integrin expression (Hannafin et al., 2006; Henshaw et al., 2006; Hsieh et al., 2002; Kim et al., 2002). Recent studies showed that cyclic mechanical loading of fibroblasts seeded on SIS-ECM can increase the expression of Col-I by five fold
(Gilbert et al., 2007) and increase the stiffness of the scaffold (Androjna et al., 2007). With the present results as a foundation, and with the incorporation of appropriate modifications, the development of a tissue engineered ACL cellular construct useful for research, and eventually for clinical applications may be possible.

\section{Acknowledgement}

We would like to cordially thank Dr. Abdou Sbihi (from the Hôpital de la Conception, Marseille, France) for having provided us with the biopsies.

\section{References}

AbiEzzi SS, Gesink DS, Schreck PJ, Amiel D, Akeson WH, Woods VL Jr. (1995) Increased expression of the beta 1 , alpha 5, and alpha $\mathrm{v}$ integrin adhesion receptor subunits occurs coincident with remodeling of stress-deprived rabbit anterior cruciate and medial collateral ligaments. J Orthop Res 13: 594-601.

Adachi N, Ochi M, Uchio Y, Sakai Y, Kuriwaka M, Fujihara A (2003) Harvesting hamstring tendons for ACL reconstruction influences postoperative hamstring muscle performance. Arch Orthop Trauma Surg 123: 460-465.

Altman GH, Horan RL, Martin I, Farhadi J, Stark PR, Volloch V, Richmond JC, Vunjak-Novakovic G, Kaplan DL (2002) Cell differentiation by mechanical stress. FASEB J 16: 270-272.

Androjna C, Spragg RK, Derwin KA (2007) Mechanical conditioning of cell-seeded small intestine submucosa (SIS): A potential tissue-engineering strategy for tendon repair. Tissue Eng 13: 233-243.

Aune AK, Hukkanen M, Madsen JE, Polak JM, Nordsletten L (1996) Nerve regeneration during patellar tendon autograft remodelling after anterior cruciate ligament reconstruction: an experimental and clinical study. J Orthop Res 14: 193-199.

Badylak SF, Arnoczky S, Plouhar P, Haut R, Mendenhall V, Clarke R, Horvath C (1999) Naturally occurring extracellular matrix as a scaffold for musculoskeletal repair. Clin Orthop 367 Suppl: 333-343.

Badylak SF, Record R, Lindberg K, Hodde JP, Park K (1998) Small intestinal submucosa: a substrate for in vitro cell growth. J Biomater Sci Polym Ed 9: 863-878.

Bellincampi LD, Closkey RF, Prasad R, Zawadsky JP, Dunn MG (1998) Viability of fibroblast-seeded ligament analogs after autogenous implantation. J Orthop Res 16: 414-420.

Bhargava MM, Beavis AJ, Edberg JC, Warren RF, Attia ET, Hannafin JA (1999) Differential expression of integrin subunits in canine knee ligament fibroblasts. J Orthop Res 17: $748-754$.

Gabriel MT, Wong EK, Woo SL, Yagi M, Debski RE (2004) Distribution of in situ forces in the anterior cruciate ligament in response to rotatory loads. J Orthop Res 22: 85-89.

Gesink DS, Pacheco HO, Kuiper SD, Schreck PJ, Amiel D, Akeson WH, Woods VL, Jr. (1992) 
Immunohistochemical localization of beta 1-integrins in anterior cruciate and medial collateral ligaments of human and rabbit. J Orthop Res 10: 96-599.

Gilbert TW, Stewart-Akers AM, Sydeski J, Nguyen TD, Badylak SF, Woo SL (2007) Gene expression by fibroblasts seeded on small intestinal submucosa and subjected to cyclic stretching. Tissue Eng 13: 1313-1323.

Hannafin JA, Attia EA, Henshaw R, Warren RF, Bhargava MM (2006) Effect of cyclic strain and plating matrix on cell proliferation and integrin expression by ligament fibroblasts. J Orthop Res 24: 149-158.

Henshaw DR, Attia E, Bhargava M, Hannafin JA (2006) Canine ACL fibroblast integrin expression and cell alignment in response to cyclic tensile strain in threedimensional collagen gels. J Orthop Res 24: 481-490.

Hodde JP, Record RD, Tullius RS, Badylak SF (2002) Retention of endothelial cell adherence to porcine-derived extracellular matrix after disinfection and sterilization. Tissue Eng 8: 225-234.

Hsieh AH, Sah RL, Paul Sung KL (2002) Biomechanical regulation of type I collagen gene expression in ACLs in organ culture. J Orthop Res 20: 325-331.

Kartus J, Movin T, Karlsson J (2001) Donor-site morbidity and anterior knee problems after anterior cruciate ligament reconstruction using autografts. Arthroscopy 17: 971-980.

Kim SG, Akaike T, Sasagaw T, Atomi Y, Kurosawa H (2002) Gene expression of type I and type III collagen by mechanical stretch in anterior cruciate ligament cells. Cell Struct Funct 27: 139-144.

Laurencin CT, Freeman JW (2005) Ligament tissue engineering: an evolutionary materials science approach. Biomaterials 26: 7530-7536.

Lindberg K, Badylak SF (2001) Porcine small intestinal submucosa (SIS): a bioscaffold supporting in vitro primary human epidermal cell differentiation and synthesis of basement membrane proteins. Burns 27: 254-266.

Liu X, Zhao Y, Gao J, Pawlyk B, Starcher B, Spencer JA, Yanagisawa H, Zuo J, Li T (2004) Elastic fiber homeostasis requires lysyl oxidase-like 1 protein. Nat Genet 36: 178-182.

Lo IK, Marchuk LL, Hart DA, Frank CB (1998) Comparison of mRNA levels for matrix molecules in normal and disrupted human anterior cruciate ligaments using reverse transcription-polymerase chain reaction. J Orthop Res 16: 421-428.

Loh JC, Fukuda Y, Tsuda E, Steadman RJ, Fu FH, Woo SL (2003) Knee stability and graft function following anterior cruciate ligament reconstruction: Comparison between 11 o'clock and 10 o'clock femoral tunnel placement. 2002 Richard O'Connor Award paper. Arthroscopy 19: 297-304.

Lowrie AG, Salter DM, Ross JA (2004) Latent effects of fibronectin, alpha5beta1 integrin, alphaVbeta5 integrin and the cytoskeleton regulate pancreatic carcinoma cell IL-8 secretion. Br J Cancer 91: 1327-1334.

McKean JM, Hsieh AH, Sung KL (2004) Epidermal growth factor differentially affects integrin-mediated adhesion and proliferation of ACL and MCL fibroblasts. Biorheology 41: 139-152.
Murray MM, Martin SD, Martin TL, Spector M (2000) Histological changes in the human anterior cruciate ligament after rupture. J Bone Joint Surg Am 82-A: 13871397.

Murray MM, Spector M (2001) The migration of cells from the ruptured human anterior cruciate ligament into collagen-glycosaminoglycan regeneration templates in vitro. Biomaterials 22: 2393-2402.

Murray MM, Spector M (1999) Fibroblast distribution in the anteromedial bundle of the human anterior cruciate ligament: the presence of alpha-smooth muscle actinpositive cells. J Orthop Res 17: 18-27.

Neurath MF, Printz H, Stofft E (1994) Cellular ultrastructure of the ruptured anterior cruciate ligament. A transmission electron microscopic and immunohistochemical study in 55 cases. Acta Orthop Scand 65: 71-76.

Palaiologou AA, Yukna RA, Moses R, Lallier TE (2001) Gingival, dermal, and periodontal ligament fibroblasts express different extracellular matrix receptors. J Periodontol 72: 798-807.

Spector M (2001) Musculoskeletal connective tissue cells with muscle: expression of muscle actin in and contraction of fibroblasts, chondrocytes, and osteoblasts. Wound Repair Regen 9: 11-18.

Spindler KP, Clark SW, Nanney LB, Davidson JM (1996) Expression of collagen and matrix metalloproteinases in ruptured human anterior cruciate ligament: an in situ hybridization study. J Orthop Res 14: 857-861.

Thomassin L, Werneck CC, Broekelmann TJ, Gleyzal C, Hornstra IK, Mecham RP, Sommer P (2005) The Proregions of lysyl oxidase and lysyl oxidase-like 1 are required for deposition onto elastic fibers. J Biol Chem 280: 42848-42855.

Yanagisawa H, Davis EC, Starcher BC, Ouchi T, Yanagisawa M, Richardson JA, Olson EN (2002) Fibulin5 is an elastin-binding protein essential for elastic fibre development in vivo. Nature 415:168-171.

Yokosaki Y, Matsuura N, Higashiyama S, Murakami I, Obara M, Yamakido M, Shigeto N, Chen J, Sheppard D (1998) Identification of the ligand binding site for the integrin alpha9 beta1 in the third fibronectin type III repeat of tenascin-C. J Biol Chem 273: 11423-11428.

\section{Discussion with Reviewers}

John Hunt: The study was fundamentally challenged by the disparity in patient profiles and therefore tissue physiology for the two groups with "normal" and ruptured ACL.

Authors: We have included information related to the pathology of the knee necessitating arthroplasty. In the discussion we did also bring up the point that the fibroblasts from the unruptured ACLs may not represent the normal condition.

Hanns Plenk: You and everybody else starts cell seeding experiments with a solution containing cells per $\mathrm{ml}$, and 
not per $\mathrm{cm}^{2}$. Therefore, you should first give this number, and then, if you feel it so important, you could calculate once this theoretical cell "density" per $\mathrm{cm}^{2}$, but keep in mind that you can never overcome the problem of distributing cells in solution uniform over a certain surface! Authors: You did not appreciate the fact that the seeding densities were formulated in cells per $\mathrm{cm}^{2}$. You thought that it was a mistake and suggested cells per $\mathrm{cm}^{3}$, or cells per ml. Actually, we really wanted to mean cells per $\mathrm{cm}^{2}$, and $\mathrm{cm}^{2}$ refers to the surface area (expansion) of SIS-ECM seeded with cells. When we wrote " $1,000,000$ cell per $\mathrm{cm}^{2}$ ", we meant that the volume of the seeding solution had been adapted in order to have $1,000,000$ cells on each $\mathrm{cm}^{2}$ of SIS-ECM.

Brian Johnstone: It cannot be concluded from immunostaining that cellular constructs 'consisted primarily of collagen type I and fibronectin'. It can be stated that these two ECM molecules are widely distributed throughout the newly formed matrix but not that they are the primary molecules. The age-related differences for elastin should be retained and a cellular construct added, indicating the lack of staining. This would also serve as a negative control for the other staining images, since no negative control is included. The vague statements that 'nearly all cells', 'most cells' and 'few cells' stained for the various integrins need to be given some better quantitative basis.

Authors: Immunostaining is not a method which brings quantitative data. However, evaluating a large amount of sections, we were able to determine numerical values to describe our observations. For example, the authors observed that the amount of SMA positive cells in the cell constructs was notably higher after 2 weeks in culture, as compared to after 1 week, and then not different anymore after 2 and 3 weeks. 